\title{
¿QUÉ ES EL PRESBÍTERO? APUNTES PARA UNA GENUINA TEOLOGÍA DEL PRESBITERADO
}

(I)

DOI: https://doi.org/10.52039/seminarios.v52i181.648

Autor: Román Sánchez Chamoso. Sacedote Operario. Profesor de Teología en Caracas y en Ciudad Bolivar de Venezuela.

Parte de la identidad del presbítero en el marco de la relación episcopado-presbiterado. Busca en la historia de dicha relación y propone una metodología. Veamos al presbítero como cooperador del obispo, compartiendo el servir al pueblo de Dios, unidos en la misma misión.

El objetivo de este trabajo es reflexionar sobre la identidad presbiteral desde la perspectiva o en el marco de la relación episcopado-presbiterado.

¿Qué es el presbítero? Una pregunta que preside y guía nuestra reflexión, insertándonos en una cadena secular de búsqueda. A los cuarenta años del concilio Vaticano II, volvemos sobre el tema del presbiterado a la vista de las cuatro décadas que han tratado de desentrañar y desplegar la doctrina conciliar. No se trata aquí en absoluto de un tratado sobre el sacerdocio ministerial ${ }^{1}$, sino de algunos puntos que consideramos neurálgicos para una teología del presbiterado propia y genuina, a la altura de nuestro tiempo. Hablaremos del presbítero, no del sacerdote, para distinguirlo del obispo y de la consiguiente teología del episcopado.

\footnotetext{
${ }^{1}$ Una visión global la presentamos, a petición del CELAM, en Ministros de la Nueva Alianza. Teología del sacerdocio ministerial, CELAM, Santafé de Bogota 1993 (En adelante: MNA).
} 
El presente estudio se inscribe en el amplio marco de la llamada crisis de identidad" del presbítero, lo que nos obliga a repensar la temática tradicional a impulso de las actuales preocupaciones. La "crisis de identidad" sobrepasa la mera reflexión teórica e incide existencialmente en quienes somos presbíteros hoy, planteando cuestiones candentes que se agitan en nuestro entorno sobre el sacerdocio ministerial. La primera cuestión, pues, es la de la identidad del presbítero².

Dos referencias se nos presentan como absolutamente centrales para elaborar una teología del presbiterado: la referencia al episcopado de la que nos ocupamos ahora y la referencia al sacramento del orden de la que pensamos ocuparnos en un trabajo posterior, pero, en ambos casos, se trata de contribuir a una renovada teología del presbiterado.

\section{Asignatura pendiente}

\subsection{Búsqueda de la identidad del presbítero en el marco de la relación episcopado-presbiterado}

Puede sorprender que hablemos de "asignatura pendiente" cuando contamos con veinte siglos de reflexión teológica "y habida cuenta de la teología del Vaticano II con la amplitud y profundidad que no tuvo antes en la Iglesia nuestro tema. Por eso, es precisa una justificación.

2 La misma teología conciliar nos impone la tarea de la comprensión actual del presbítero. Cf. R. SÁNCHEZ CHAMOSO, "Re-situar" al presbítero en el nuevo contexto eclesial-ministerial" en Seminarios 69 (1978)311-337. La expresión "crisis de identidad" ha hecho fortuna: cf. R. .SÁNCHEZ CHAMOSO, "Identidad sacerdotal y "crisis de identidad” en Teología IUSI. 11 (1993) 43-74. W. KASPER, "Presentación” en Concíliun 74 (1972) 5-6.

El magisterio de la Iglesia ha abordado el tema de la "crisis de identidad". Leemos en la Exhortación apostólica "Pastores dabo vobis" de Juan Pablo II: "Esta crisis había nacido en los años inmediatamente siguientes al concilio. Se fundaba sobre una comprensión errónea, y tal vez hasta intencionadamente tendenciosa, de la doctrina del magisterio conciliar. Y aquí está indudablemente una de las causas del gran número de pérdidas padecidas entonces por la Iglesia" (n. 11) (En adelante: PDV). Juan Pablo II reconoce la existencia de esta crisis: cf. Carta a los sacerdotes con ocasión del día del Jueves Santo de 1990, n.2. Otros documentos del magisterio: cf. CONGREGACIÓN PARA EL CLERO, Directorio para el ministerio y la vida de los presbíteros, Tipografía Vaticana, Roma 1994, Cap. I: "Identidad del presbítero". En PDV (nn.3 y 11) se enumeran los documentos del magisterio que han tratado de la actual situación del presbítero: LG, CD, PO, OT, Ratio Fundamentalis Institutionis Sacerdotalis, Roma 1970 y Sínodos de los Obispos de 1967 y 1971. 
Precisemos, en primer lugar, el ámbito de nuestro trabajo. ¿De qué tratamos en concreto? El intento es buscar la propia identidad del presbiterado. Para ello, el marco de reflexión de este trabajo será, sobre todo, la relación episcopado-presbiterado, que tiene una larga y azarosa historia, una relación dialéctica con una trayectoria complicada y con alternativas 3 . Hoy se plantea de nuevo el tema desde otras coordenadas a la luz de la teología del episcopado del Vaticano II. Algo queda claro si nos atenemos a la enseñanza de la historia: para llegar a la identidad del presbiterado hay que contar con el ministerio episcopal, pues ambos discurren dentro de una necesaria relación.

Daremos inicialmente dos pasos para centrar el problema que abordamos, siguiendo el trayecto que va de Trento al Vaticano II.

\subsection{Trento: aportes y límites}

Trento fue un hito miliar y, hasta el Vaticano II, una pauta segura que gozaba de común aceptación oficial. Pero quedaron muchos hilos sueltos. Trento no quiso o no pudo ofrecer una doctrina completa sobre el sacramento del orden. Los padres del concilio eran conscientes de que el decreto tridentino no dice todo lo que se podría decir, limitados por su opción metodológica de responder a las innovaciones de la reforma 4 .

Atado teológicamente a la escolástica, para Trento la categoría de sacerdocio es la clave del desarrollo doctrinal5. La institución del sacra-

¿En qué consistió esa "comprensión errónea" de que habla PDV y quiénes la protagonizaron? He aquí una pregunta que ha originado numerosos trabajos sobre el complejo problema de la "crisis de identidad" del presbítero. Por nuestra parte, nos preguntamos si no estará también en la base del fenómeno un inadecuado modo de entender la relación entre el episcopado y el presbiterado. Si fuera así, el trabajo que ahora emprendemos puede aportar datos para una respuesta.

3 Cf. mi exposición sobre el tema en Iglesia-comunión e Iglesia ministerial. ComuniónMinisterio eclesial-Presbiterio, IUSI, Caracas 1997,294-312 (En adelante: ICIN). "La referencia al episcopado para entender el presbiterado es una constante en la historia del ministerio ordenado, pero las bases teológicas de la relación son diversas de acuerdo con la teología de la época. En nuestros días, es también un punto central para elaborar la teología del presbiterado, que debe hacerse desde las posiciones actuales de la teología" (Ibid. 294).

${ }^{4}$ En estos términos expresa Trento sus propios límites: "Doctrina católica y verdadera acerca del sacramento del orden, para condenar los errores de nuestro tiempo"(DS 1763).

5 EL Decreto dogmático de Trento (DS 1763-1778) utiliza el término sacerdos en nueve ocasiones una sola vez el de presbyter (para distinguir al presbítero del obispo). Esta preferen- 
mento es llamada por Trento institución del sacerdocio, y a los ministros ordenados se les llama "sucesores (de los apóstoles) en el sacerdocio"6. "Desde la época de los grandes escolásticos, la categoría de sacerdocio es la categoría madre del sacramento del orden"7. Pero sacerdos es igualmente el obispo y el presbítero en virtud del sacramento (potestas ordinis); la diferencia entre obispo y presbítero, y la superioridad del primero sobre el segundo, radica en las funciones de enseñar y de gobernar propias del obispo, que no derivan de la ordenación, sino de la jurisdicción o investidura que el Papa ha conferido solamente al obispo (potestas iurisdictionis). Hasta aquí Trento. La teología del episcopado era muy embrionaria, el episcopado no se entendía como sacramentum, sino como "dignidad" y "honor" que se añadía desde fuera al sacerdocio ${ }^{8}$. La superioridad del episcopado sobre el presbiterado, expresamente afirmada por Trento, se debe al poder jerárquico que le viene via_jurisdictionis ${ }^{9}$.

cia terminológica la invertirá el Vaticano II, sobre todo en PO, a comenzar por el título del documento conciliar.

Sobre la evolución de la terminología en el Vaticano II, cf. R. SÁNCHEZ CHAMOSO, MNA, 21-23.35-39. El título "Presbyterorum ordinis" muestra a las claras una intención deliberada: presbítero más bien que sacerdote_(como había hecho Trento),considerando al presbítero en lo que tiene de propio y diferencial, no en lo que tiene en común con el obispo por ser ambos sacerdotes. La identidad del presbítero se comienza a delinear. La estadística viene en nuestra ayuda: PO usa presbyter (ordinariamente en plural) 12 veces, contra 32 veces el sustantivo sacerdos-sacerdotium y 15 veces el adjetivo sacerdotalis (Cf. B. SESBOUÉ, "Pour une theologie oecumenique, Cerf, Paris 1990, 357).

6 DS 1764. El sacerdocio era el punto álgido cuestionado por Lutero, juntamente ligado a él con el sacrificio de la misa, que explica por qué Trento resalta la estrechísima unión entre sacerdocio y sacrificio (Cf.DS 1764), de donde el "sacerdos ad cultum", imagen dominante hasta el Vaticano II.

${ }^{7}$ B. SESBOUÉ (Dir), Historia de los dogmas, III, Secretariado Trinitario, Salamanca 1992, 145 (En adelante: HD).

8 Por una parte, la gran tradición teológica, desde Jerónimo al Ambrosiaster hasta los grandes escolásticos Alejandro de Hales, Alberto Magno, Buenaventura, Tomás de Aquino... no reconocían al episcopado como sacramento. Por otra parte, en el seno del concilio de Trento surge un enconado enfrentamiento entre los padres que defienden el episcopado de iure divino y los representantes del Papa que se oponen a esta tesis, negándose el mismo Papa a que se abordara en profundidad la cuestión (Cf. B. SESBOUÉ, HD, 144). El episcopado se entendía corno "dignitas" conferida por investidura jurídica del Papa El presbítero era el "sacerdote" por antonomasia (Cf. Y-M. CONGAR, L'Eglise de S. Augustin a l'époque moderne, Paris 1970, 169174.248-252). Se da aquí curiosamente la inversión de la idea dominante en los cinco primeros siglos que consideraba al obispo el "sacerdote" por antonomasia, como veremos más adelante.

9 Cf. DS 1764-1777 "Potestad de confirmar, ordenar y hacer otras muchas cosas, en cuyo desempeño ninguna potestad tienen los otros de orden menor". 
La herencia de Trento llega hasta el Vaticano II: la potestas ordinis iguala a obispo y presbítero, la potestas iurisdictionis los diferencia. El punto de partida es el sacerdocio. Para los escolásticos y para Trento, el episcopado no es un sacramento, sino un sacramental, y va acompañado de una investidura otorgada por el Papa por la que confía al obispo la potestas iurisdictionis sobre una diócesis. Con todo, un punto capital queda firmemente asentado: hay un único sacramento del orden. Esto sigue siendo determinante para establecer la relación entre episcopado y presbiterado.

Pero el problema teológico queda vivo en el interior de la Iglesia católica hasta el Vaticano II. Nos hallamos ante un episcopado teológicamente débil y jurisdiccionalmente fuerte. Será el Vaticano II el que avance sobre esta situación extraña y anómala al proclamar la sacramentalidad del episcopado (LG 21), puesto que, como veremos, va a ser decisivo para la teología del sacramento del orden, más en concreto para la teología del episcopado y, necesariamente vinculada a ésta, para la teología del presbiterado. Estos nuevos datos teológicos hacen que la identidad del presbítero se halle "en camino", que sea "asignatura pendiente" aún ${ }^{10}$.

1.3. El Vaticano II abre nuevos caminos en la relación episcopadopresbiterado

La herencia de Trento va a ser superada. "El Vaticano II invertirá este movimiento del pensamiento, exponiendo la doctrina del ministerio a partir del episcopado"11. El cambio es profundo: de comenzar partiendo del sacerdocio a comenzar partiendo del episcopado como plenitud del sacramento del orden ${ }^{12}$. Un punto clave del nuevo planteamiento va a ser la sacramentalidad del episcopado enseñada por el Vaticano II.

El malestar de los teólogos ante la situación heredada era doble. Por una parte, el obispo era superior al presbítero tan solo por razón de la

10 "El concilio de Trento mantendrá un silencio total sobre todos los puntos que cuatro siglos más tarde serán objeto privilegiado de reflexión del Vaticano II sobre la Iglesia” (B. SESBOUÉ, HD, 145).

11 Ibid 148.

12 Cf. memorable intervención en el concilio de Mons. GUERRY, portavoz del episcopado francés, en Acta Synodalia, vol.II. Pars II, p.89. 
jurisdicción y no por razón del orden, por lo que se vinculaba a un mero acto jurídico la adquisición de los poderes episcopales. En segundo lugar, la potestad episcopal no se fundamentaba en el derecho divino, sino en la misión canónica recibida del Papa. Quedaba así una materia pendiente que incentivó a la eclesiología del siglo XX para resolverla13.

El concilio Vaticano II asienta tres puntos referentes al episcopado que necesariamente abren nuevos frentes, plantea nuevos problemas y hacen que se replantee la naturaleza del presbiterado. En primer lugar, rompe una línea multisecular al proclamar, por primera vez en la doctrina oficial del magisterio, el episcopado como sacramento. Además, entiende el episcopado como "plenitud del sacramento del orden, sumo sacerdocio y culmen del ministerio sagrado". En tercer lugar, reitera la idea de los presbíteros como "cooperadores del orden episcopal". Por último, podemos señalar como pierde vigor la distinción entre "potestas ordinis" y "potestas iurisdictionis", que tanta vigencia tuvo desde el siglo XII. Son estos unos datos que van mucho más allá de Trento y de la consecuente teología del presbiterado vigente oficialmente. Por tanto, nuestro tema se replantea en términos radicales en lo referente a la relación obispo-presbítero, dada la estatura teológica adquirida por el episcopado.

Esto es lo que tendremos que estudiar con detención. ¿Ha retrocedido la posición del presbítero si la compararnos con la posición de Trento? Esto es lo que podría colegirse de algunas fórmulas actuales que insisten en la comprensión del presbiterado "a partir del episcopado", situando el nudo del tema, quizá de modo inconsciente, en la dependencia respecto del episcopado, quizá arrastrados por una "euforia" episcopal que necesita ser discernida con rigor. Téngase en cuenta que, así como hay "códigos sociales" que marcan espontáneamente el comportamiento social, podríamos hablar de "códigos clericales" que hacen del obispo el todo, o casi todo, del sacramento del orden. ¿Qué espacio y papel propios le queda al

13 Para la sacramentalidad del episcopado antes del Vaticano II, cf. G. NICOLUSSI, " $L a$ sacramentalitá dell'episcopato. Brevi cenni sulle diverse posizioni riguardanti la sacramentalitá dell'episcopato nella teología preconciliari' en Ephemerides Theologicae Lovanienses 47(1971) 10-22. Una apuesta decidida a favor de la sacramentalidad del episcopado se debe a J. LECUYER, "La grace de la consecration épiscopale" en Revue des Sciencies Théologiques et Philosophiiques 36(1952)339-417. Para después del Vaticano II, entre la abundante bibliografía, cf. C. POZO, "Teología del episcopado en el capítulo 32 de la constitución De Ecclesia" en Estudios Eclesiásticos 40(1965)139-161. 
presbítero? He ahí un punto capital que trataremos más adelante con cierta extensión.

\subsection{Configuración del ministerio en la Iglesia: vertientes o referencia.}

En la configuración de todo ministerio eclesial entran en juego, entre otras, dos vertientes capitales: cometido o competencia propios de cada ministerio y relación con otros ministerios. Consiguientemente, la alteración de un ministerio tiene necesariamente repercusión en los otros ${ }^{14}$. Ahora bien, el ministerio presbiteral está flanqueado por los ministerios del episcopado y del laicado, dicho de otra manera, el presbítero se halla eclesialmente entre el obispo y el laico.

El Vaticano II ha desarrollado ampliamente las teologías del ministerio episcopal y laical y no en la misma medida la teología del ministerio presbiteral como ya se denunció en los debates conciliares ${ }^{15}$; en consecuencia, el presbítero queda en situación precaria y ante interrogantes que le cuestionan en profundidad: ¿Qué puesto y papel le corresponden en una Iglesia que ha logrado una notable estatura teológica del episcopado y del laicado? ¿Es esencialmente y ante todo su ministerio dependiente del obispo? Inmediatamente después del concilio aparecieron títulos significativos tales como “¿Para qué sacerdotes?”16. Estudios teológicos y esta-

${ }^{14}$ Cf. R. SÁNCHEZ CHAMOSO, a.c. en Nota 2 y MNA, 77-85.

15 El Vaticano II se ocupó del presbiterado prevalentemente en LG 28 y en PO. La historia de la elaboración de "Presbyterorum ordinis" muestra que no se preparó con la hondura de otros documentos conciliares, a pesar de que el Proemio habla de "tratar despacio y más a fondo de los presbíteros". El documento sufrió ocho redacciones -de 8 de diciembre de 1965 a 12 de noviembre de 1965- en que es aprobado por el concilio. Reiteradamente se acusaba al documento de ser muy disciplinar y poco teológico. Hacia el final, se le imprime una nueva orientación y se le asigna el titulo actual. Alguna voz se levantó para denunciar que el concilio había olvidado a los presbíteros al precio de insistir en el episcopado y en el laicado. En conclusión, en PO, así como en LG 28, CD y OT se encuentra un rico material, pero más bien como "disiecta membra" que no logran articular una orgánica teología del presbiterado. Esta hipoteca la pagará el postconcilio.

16 Cf. A. ANCEL, "Un nuevo tipo di sacerdote" en AA.VV., Concilio vivo, Ancora, Milano 1967, 214-223; Id., "Il sacerdote nel mondo contemporáneo" en AA. VV., I sacerdoti nel pensiero del Vaticano II, Roma 1966; G. M. CARRONE, Il prete di domani, Leumann, Tormo 1969; T. CLOIN, "Un nuevo tipo de sacerdote" en Medellín 3(1975)373-379; R. DUBERT, "Comunidades sin sacerdotes" en Sal Terrae 63 (1975) 284-289; E. SCHILLEBEECKX, "Necesidad de buscar un nuevo tipo de ministerio eclesial y Teología del ministerio eclesial" en 
dísticos serios apuntan a la misión del presbítero en la Iglesia actual como el punto focal que hay que dilucidar, y que ha contribuido decisivamente a la llamada "crisis de identidad" del postconcilio"17. La teología postconciliar se esfuerza por "re-situar" al presbítero en una Iglesia pluri-ministerial lo que, en la práctica, nos habla de la necesidad de una renovada teología del presbiterado.

"Asignatura pendiente" figura como cabecera de este apartado. Las líneas que preceden justifican dicho título. A partir de esta toma de conciencia, avanzaremos con algunas propuestas que aporten respuesta al problema. Comenzaremos con la metodología que adoptamos, que es más que simple metodología como tendremos ocasión de ver.

\section{Metodología}

Seguimos con el tema de la actual visión del presbiterado en relación con el episcopado

\subsection{Principio directriz metodológico}

La cobertura fundamental nos la va a proporcionar el Vaticano II en una interpretación del concilio hecha por el mismo concilio, por lo que deliberadamente cederemos la palabra al concilio, dejando que sea él quien hable y gravitando sobre citas textuales ${ }^{18}$.

La misión de la Iglesia, Sígueme, Salamanca 1971, 465ss. 477ss.; F. .URBINA de la QUINTANA, Hacia una nueva figura histórica del ministerio. Vocaciones para una comunidad misionera, EDICEP, Valencia 1974; íd., "Vocaciones para el futuro" en Seminarios 21 (1975) 43-68; E. ETCHEGARAY, "Verso una nuova imagine del sacerdote" en AA. VV., Il prete per gli uomini d'oggi, A.V.E., Roma 1975, 879ss.

'El Vaticano II redefinió ciertamente de nuevo la Iglesia, los laicos, pero falta la definición del sacerdote" (P. M. ZULEHNER, "Las vocaciones pastorales antiguas y nuevas en la Iglesia" en Seminarios 23(1977)203) "El concilio ha situado en una postura angosta y molesta la figura del presbítero entre la del laico en auge y cada vez con más responsabilidades y la del obispo fuertemente revalorizada. La potenciación de estos ministerios colaterales al del presbítero hace que éste vea reducida su estatura, aunque no se haya pretendido en absoluto tal objetivo" (R. SÁNCHEZ CHAMOSO, MNA, 101-102).

17 Cf. E. COLAGOVANNI, Crisi vere e false nel ruolo del prete oggi. Uno studio sociologico a livello mondiale, Città Nova Editrice, Roma 1973.

18 ¿Vamos contra corriente en esta opción metodológica? Se ha escrito que "es raro, en este momento, que el trabajo teológico se fundamente en los textos del magisterio" (E. VILANO- 
Se hace más necesaria esta metodología porque el concilio no pudo lograr en cada caso la claridad anhelada, por lo que determinados pasajes habrá que interpretarlos a la luz y con la ayuda de otros. Pero, más importante aún, optamos por esta metodología porque hay coherencia interna en la globalidad de la doctrina conciliar aunque no siempre aparezca a primera vista, lo que desautoriza cualquier lectura en clave alternativa. Por tanto, no se busquen contradicciones donde solo hay diversas formulaciones, necesitadas de una lectura atenta y minuciosa que las haga compatibles ${ }^{19}$. Más adelante nos ocuparemos de algunos de estos casos.

Atenderemos de modo particular a la exégesis del concilio con la ayuda de "Pastores dabo vobis", el documento del magisterio, por otra parte netamente colegial, más extenso y maduro sobre nuestro tema ${ }^{20}$.

\subsection{Relación entre episcopado y presbiterado ${ }^{21}$}

2.2.1. De la relación primado-episcopado a la relación episcopadopresbiterado

En primer lugar, vamos a tener presente como opción metodológica y como horizonte referencial la doctrina del Vaticano II sobre la relación primado-episcopado, verdadero foco del Cap. III de LG y uno de los frutos más granados del concilio. El esclarecimiento conciliar al respecto es también iluminador para nosotros ahora.

VA, Historia de la teología cristiana, III, Herder, Barcelona 1992,956). Pero tampoco debemos olvidar el juicio del Sínodo de los Obispos de 1985 sobre el Vaticano II: "Celebrar, verificar y promover el Vaticano II", pues es la "máxima gracia del siglo" y la charta magna de la Iglesia católica para el presente y el futuro (Concilium 208 (1986): Número monográfico sobre la valoración del Sínodo extraordinario de 1985). "El concilio es la gran gracia de la que la Iglesia se ha beneficiado en el siglo XX. Con el concilio se nos ha ofrecido una brújula segura para orientarnos en el camino del siglo que comienza" (JUAN PABLO II; Novo millennio ineunte, n.57).

${ }^{19}$ Nos basaremos en LG 28, CD, PO, OT...documentos conciliares que tratan del presbiterado y que nosotros analizaremos en lo referente a la relación episcopado-presbiterado.

20 ¿Qué significado tiene PDV?. Se dice en la dedicatoria del documento que es "fruto del trabajo colegial del Sínodo de los Obispos de 1990". Juan Pablo II afirma que "recoge la doctrina del concilio Vaticano II y también la reflexión sobre las experiencias de los veinticinco años transcurridos desde su clausura" y se propone "poner en práctica la doctrina conciliar sobre este tema y hacerla más actual e incisiva en las circunstancias actuales" (n.2).

21 Relación dialéctica con una trayectoria complicada, cf. R. SÁNCHEZ CHAMOSO, ICIN, 294-302; Id., MNA, 271-274. 
El Vaticano II ha logrado el anhelado equilibrio eclesiológico al superar la imagen piramidal de la Iglesia con la concentración de todos los poderes en su vértice. Se ha restituido al episcopado la importancia y el papel que le corresponde (Cf. CD 4-7) y todo el poder ordinario, propio e inmediato requerido para el ejercicio de su cargo pastoral (Cf. LG 27a; CD 8). Un pasaje conciliar puede resumir el paso dado: "Los obispos no deben considerarse como vicarios de los Romanos Pontífices, ya que ejercen potestad propia y son, en verdad, los jefes de los pueblos que gobiernan" (LG 27b), "son vicarios y legados de Cristo" (LG -27a). Se solventaba así un punto delicado arrastrado durante siglos y que Trento no supo afrontar.

Pero nuestro tema de estudio no es la teología del episcopado, sino la del presbiterado. Si tenemos en nuestro horizonte la primera es porque, como veremos en la aplicación de la metodología elegida, de alguna manera se reproduce hoy la problemática primado-episcopado en el plano de episcopado-presbiterado; la solución conciliar dada al primer binomio nos proporciona luz y base para afrontar el segundo binomio, salvados y respetados lógicamente los distintos niveles de uno y otro. Lo dicho nos autoriza a establecer un cierto paralelismo o simetría entre los binomios Papa-obispos y obispo-presbíteros ${ }^{22}$; el mismo sacramento que hace al Papa cabeza del colegio episcopal y a los obispos miembros del colegio (colegialidad basada en la sacramentalidad), hace al obispo cabeza del presbiterio y a los presbíteros miembros del mismo. En ambos casos, el acento recae sobre el sacramento.

\subsubsection{Recurso a la "analogía de la fe"}

Encontramos apoyo para nuestra metodología en el concilio Vaticano I y su doctrina sobre la "analogía de la fe" Hay que proceder "de acuerdo con la fe" (Rom 12,6), "conforme al grado de fe que Dios le ha concedido" (Rom 12,3), lo que se traduce en nuestro caso proceder en concordancia con el magisterio oficial del Vaticano II sobre el episcopado, no actuando arbitrariamente, sin medida y control, sino, como recomienda el Vaticano I, actuando "sobriamente" (D8 3016)

22 He propuesto esta "simetría-analogía” en ICIM, 302-310. 
El Vaticano I propone como una vía de acceso al misterio "la conexión de los misterios mismos entre si", o "analogía de la fe" (DS 3016). Recurrimos a esta pista para adentramos en la teología del presbiterado al basarnos en la analogía-simetría que pueda establecerse entre la teología del episcopado (expresamente enseñada por el Vaticano II) y, "a la luz de ella", la teología del presbiterado que es posible elaborar hoy. Al tratarse de analogía, se da una proporción o semejanza entre realidades diferentes, pero con algo en común ${ }^{23}$. Es decir, a la luz de la teología del episcopado se ilumina la del presbiterado, vamos de lo más claro y explicito a lo menos explícito, pero también presente en el concilio. Porque el Vaticano II nos proporciona abundante datos valiosos, pero no una elaboración sistemática como lo hizo con la teología del episcopado, no ha logrado armonizar expresamente la autoridad episcopal y el papel del presbítero. No obstante, hay una "mutua inmanencia" entre episcopado y presbiterado (al modo como lo hay entre la Iglesia universal y la Iglesia particular) que necesita ser desarrollada por la teología.

Es posible descubrir un rico paralelismo (analogía-simetría) entre el episcopado y el presbiterado, tomando como base la sacramentalidad, la colegialidad, la corresponsabilidad pastoral, el ministerio, la comunión e incluso la jurisdicción, de donde se pueden deducir una serie de propuestas teológicas basándonos en la "analogía de la fe" 24 . Con ello se da un paso importante para determinar la identidad genuina del presbiterado.

$\mathrm{Al}$ recurrir a esta simetría-analogía, obedecemos en el fondo al Vaticano II que nos presenta el presbiterado en referencia al episcopado; procedemos por vía de relacionalidad, un concepto que se abre paso en la teología renovada del presbiterado25. La teología del presbiterado se articula

23 Cf. L. SCHEFFCZYK, "Analogía de la fe" en K.RAHNER et alii (Dirs), Sacramentum mundi. Enciclopedia Teológica, I, Herder, Barcelona 1976, 138-143: es un principio católico de conocimiento que tiende hacia la unidad entre lo claro (aquí teología del episcopado del Vaticano II) y lo buscado (aquí teología del presbiterado). Se conoce, aclara y profundiza una cosa a través de otra; hay inducción teológica. Es un principio heurístico porque lleva a nuevos conocimientos. Es un principio de integración, que descubre la correspondencia entre lo establecido (aquí el episcopado) y lo buscado (aquí el presbiterado) Se da, pues, una relación de dependencia entre un "primer analogado" (episcopado) y "analogados secundarios" (presbiterado).

24 Cf. R. SÁNCHEZ CHAMOSO, ICI, 310: cuadro sintético-sinóptico que plasma este paralelismo.

25 Cf. R. SÁNCHEZ CHAMOSO, MNA, 439-446. PDV n.12 enfatiza el aspecto esencialmente relacional de la identidad del presbítero. 
y despliega en un tejido o red de relaciones, siendo una de ellas la relación con el ministerio apostólico representado eminentemente en el episcopado $^{26}$. Esto debe tener aplicación en el plano más cercano de la Iglesia particular y, en concreto, en el tema de la colegialidad. Con precisión teológica y canónica ha podido escribir un canonista: "La colegialidad del presbiterio con el obispo habrá de adoptar unas formas análogas a las que realice la colegialidad de los obispos con el Papa. La relación del obispo con su presbiterio habrá de entenderse en sentido análogo con la relación Papa-obispos"27.

\subsection{3. ¿El presbiterado "a partir de" o "a la luz de" el episcopado?28}

Abordamos un punto clave de nuestra metodología. Se ha generalizado la idea de que el presbiterado se debe entender "a partir de" el episcopado, viendo aquí el nuevo y original giro dado por el Vaticano II para elaborar la teología del presbiterado. El giro operado es evidente y su novedad ha sido debidamente resaltada por la teología post-conciliar. Ya hemos indicado que durante siglos se tomó el sacerdocio como punto de partida y este se pone ahora en el episcopado. Puede hablarse de amplio consenso al respecto. Se ha rebasado la relación del presbiterado con el episcopado en sentido prevalentemente jurídico y se ha planteado el tema con base en la teología del Vaticano II sobre los ministerios, sobre la "eclesiología de comunión" y sobre el principio de corresponsabilidad con el Evangelio y con la Iglesia.

No obstante, considero que la expresión "a partir de" necesita una precisión e interpretación matizada y que no siempre se hace, acordes con el Vaticano II, pues con dicha expresión se corre el peligro de volver a situaciones antiguas bajo un nuevo ropaje terminológico. Este peligro es real, por lo que hacemos una precisión: es más correcto hablar de "a la luz de" que "a partir de". Compartimos el planteamiento de Congar cuando, refiriéndose a los temas que esperan nuevo desarrollo apenas terminado el concilio, escribe: "Será menester desarrollar la idea del presbiterado bajo

26 Cf. R. SÁNCHEZ CHAMOSO, MNA, 227-276.

27 T. GARCÍA BARBERENA, "Colegialidad en el plano diocesano. El presbiterio occidental" en Concilium 8 (1965)31-32.

${ }^{28}$ Reelaboramos las principales ideas expuestas en ICIH, 243-247. Cf. B. SESBOUÉ, HD, 144.147. 
la luz del tema del obispo tal como se enfoca en la misma constitución "Lumen gentium" como en el decreto "Christus Dominus"29.

Se trata de algo más que de un mero matiz, se trata de un enfoque con serias consecuencias teológicas. En efecto, decir a partir de podría entenderse como "derivado de" (el episcopado como causa fontal), como si el episcopado fuera la raíz o fuente de la que mana el presbiterado o como si el episcopado hiciera participe al presbiterado de algo que solo él tiene; eso supondría ignorar que es el sacramento la matriz, fuente y cuna del presbiterado ${ }^{30}$. En cambio, decir a la luz de o bajo la luz de (Congar) significa que la doctrina conciliar sobre la relación primado-episcopado nos proporciona un antecedente y arroja luz (por analogía) para el correcto planteamiento de la relación episcopado-presbiterado o, dicho con otras palabras, que la nueva situación del episcopado respecto del primado se puede aplicar de modo análogo (como analogado principal) a la situación del presbiterado respecto del episcopado. Lo que en cualquier caso hay que dejar a salvo es al sacramento del orden como fuente del presbiterado (sacramentalidad del presbiterado).

Otro dato debemos tener en cuenta. En ambos casos -“a partir de" el episcopado o "a la luz de" el episcopado- se afirma la necesaria referencia al episcopado, pero el alcance teológico de esa referencia es muy distinto en un caso y en otro, es decir, en ambos casos se tiene en la base la teología del episcopado, pero la función que se le asigna es muy diferente.

2.2.4. Algunos ejemplos para ilustrar la nueva relación episcopadopresbiterado

A partir de las precisiones precedentes, ahora se plantea en la teología

29 Y-M. CONGAR, “A modo de conclusión” en G. BARAUNA (Ed), La Iglesia del Vaticano II, II, Herder, Barcelona 1968, 130) (El subrayado es nuestro).

${ }^{30}$ Así ocurre en algunas publicaciones al decir que el presbítero es emanación necesaria del ministerio episcopal", o que "solo existe en cuanto deriva del obispo la propia función sacramental y pastoral" (E. CORECCO, "Sinodalidad" en G. BARBAGLIO - DIANICH (Dirs), Nuevo Diccionario de Teología, II, Cristiandad, Madrid 1982) Insistimos en este punto metodológico. Así como el poder de los apóstoles les fue dado por Cristo y no por Pedro y el de los obispos les es dado por el sacramento y no por el Papa, pari modo hemos de decir que el poder de los presbíteros les es dado por el sacramento y no por el obispo. Todavía pesa mucho Trento que, si no logró el equilibrio del Obispo de Roma y el del episcopado, tampoco lo logró entre el episcopado y el presbiterado. 
y en la Iglesia elaborar la teología del presbiterado con una metodología consistente en "prolongar" hasta el presbiterado las intuiciones y aportes del Vaticano II sobre el episcopado. El concilio nos ofrece suficiente cobertura teológica para la empresa con su teología ministerial. Avanzamos algunas ideas que se desarrollarán más ampliamente después con el único fin de ilustrar, a modo de ejemplo, lo que pretendemos con la metodología propuesta.

a) Asumimos sin reservas que el presbítero es "cooperador del orden episcopal", pero hemos de entenderlo "a la luz de" y sobre la base como el Vaticano II establece la cooperación-colaboración entre el primado y el episcopado. El obispo no es un delegado del Papa, es vicario y legado de Cristo en virtud del sacramento del orden.

Por lo tanto, no puede hacerse gravitar su ser ministerial sobre dicha colaboración como último fundamento teológico, dejando en la penumbra el fundamento propiamente sacramental. La relación nueva entre primado y episcopado se puede expresar más fielmente en términos de "corresponsabilidad" que en términos de "sumisión", para ser de esta forma fieles a "la forma de gobierno que Cristo Señor estableció en su Iglesia" (LG 27b) y para salvar la "naturaleza y la forma colegial del orden episcopal" (LG 22a). Queda superada así por todos los costados el obispo como simple colaborador y delegado del Papa. Pues bien, el mismo esquema argumental, "mutatis mutandis", creemos que debe aplicarse a la cooperación del presbítero con el obispo, pues se asienta en idéntico trasfondo teológico-sacramental.

b) El Vaticano II habla de los oficios de los obispos de regir y enseñar para lo que gozan de "potestad que personalmente ejercen en nombre de Cristo y es propia, ordinaria e inmediata, aunque su ejercicio esté regulado en definitiva por la suprema autoridad en la Iglesia y pueda ser circunscrita dentro de ciertos límites"31. Pues bien, al hablar de los presbíteros, se dice que "dependen de los obispos en el ejercicio de su potestad" 32. Nótese que en ambos casos se habla del "ejercicio del ministerio", no de

${ }^{31}$ LG 27a. (El subrayado es nuestro). Todo el Cap. III de LG rezuma esta idea, expuesta en registros variados.

32 LG 28a (El subrayado es nuestro). 
su fuente o raíz, que indudablemente es el sacramento del orden. ¿Cómo no ver aquí una íntima afinidad en la relación que tanto el episcopado como el presbiterado tienen con la correspondiente cabeza de su ordo? Vislumbramos en el fondo la idea o soporte de "comunión", que en nuestro caso es una comunión operativa ${ }^{33}$, aplicable por la misma razón teológica al episcopado y al presbiterado

c) El Vaticano II ha planteado en otras coordenadas la relación primado-episcopado, pasando del signo de sumisión-dependencia-obediencia al signo de comunión-corresponsabilidad. No de otra forma habrá que entender la relación episcopado-presbiterado, aunque la letra del concilio no sea en este caso tan explícita, e incluso a veces tenga formulaciones ambiguas necesitadas de explicación y que no se deben asumir en su literalidad para ser fieles al espíritu conciliar. Es lo que nos proponemos hacer en este trabajo.

d) Hay otras razones teológicas que inducen a resaltar la relación del presbiterado con el episcopado. Por una parte, el presbítero, en palabras de PDV, es" esencialmente relacional" y se define como "una red de relaciones" (n.12), siendo una de ellas el "ministerio apostólico" representado en el episcopado ${ }^{34}$. Por otra parte, la realidad fundamental desde la que se entiende al presbítero y al obispo es la realidad del único sacramento del orden, o sea, la unidad institucional del ministerio ordenado, dato firme contenido tanto en Trento como en el Vaticano II ${ }^{35}$, pero sólo el episcopado tiene la "plenitud del sacramento del orden" y la "cumbre del ministerio sagrado" (LG 21b). Esto pide que los demás ministerios ordenados deban guardar una peculiar relación con esa "plenitud" y "cumbre".

33 PDV n. 17 lo formula claramente: "El ministerio de los presbíteros es, ante todo, comunión y colaboración responsable y necesaria con el ministerio de los obispos en su solicitud por la Iglesia universal". Obispo y presbítero, por tanto, se hallan conjuntamente vinculados a la misión de la Iglesia universal como razón de ser de su intencionalidad última; el presbítero no es. ordenado, ante todo, para ser auxiliar de la persona del obispo, sino que aporta su ministerio al oficio pastoral del obispo en la Iglesia universal y en la particular.

34 Cf. R. SÁNCHEZ CHAMOSO, MNA, 252ss.

35 Trento habla de una única "jerarquía eclesiástica instituida por disposición divina” (divina ordinatione: DS 1767.1776) y el Vaticano II habla de "ministerio eclesiástico de institución divina" (divinitus institutum: LG 28a). Ambos se refieren a la unidad básica del ministerio, a una realidad única producida por el único sacramento del orden. 
e) ¿Cuál es la cualificación del ministerio presbiteral o de la identidad propia del presbítero?

Esto es lo que indaga la teología actual ${ }^{36}$. El episcopado, como grado supremo del sacramento del orden -"plenitud" y "cumbre"-habrá que entenderlo como el primer analogado, en referencia ("a la luz de") al cual habrá que entender los demás grados como analogados secundarios. Los grados deben comprenderse a partir del grado superior. Es lo que en el fondo hacen Trento y el Vaticano II. Pero no se pronuncian sobre el origen o fundamento (¿divino?, ¿eclesiástico?) de esta distinción de grados, no afirman que se derive de la institución por Cristo. Se ha dejado a la teología dar una explicación. Pueden venir de una disposición eclesial, como otros elementos que tienen que ver con la gestación de los sacramentos ${ }^{37}$.

Conclusión. Cerramos el tema de nuestra metodología con estas palabras escritas hace algunos años: "En nuestro planteamiento, el episcopado actúa como presupuesto metodológico por ser doctrina firme y explícita del Vaticano II, y el presbiterado, tal como lo presentamos aquí, es una propuesta teológica nuestra. Si hemos entendido correctamente la doctrina oficial sobre el episcopado, creemos que la derivación que hacemos al presbiterado es legítima y consistente teológicamente. Toda nuestra reflexión se mueve en el .ámbito puramente teológico-eclesial y no es deudora de paradigmas ajenos a la revelación"38.

\section{Los presbíteros, "cooperadores del orden episcopal"}

Llegamos así al objetivo focal de nuestro estudio. Este punto necesita una atenta consideración porque lo consideramos básico para determinar él tipo de relación entre episcopado y presbiterado. Anticipemos que la

\footnotetext{
36 "La opción principal del concilio, que consiste en tratar del ministerio ordenado o jerárquico a partir del episcopado, y no ya como en Trento a partir del presbiterado, conduce a situar de nuevo el sacerdocio ministerial como una cualificación de este ministerio y no ya como lo que lo define pura y simplemente (H. BOURGEROIS, "Los sacramentos según el Vaticano II" en B. SESBOUE, HD, 197).

37 Ibid., 198.

38 R. SÁNCHEZ CHAMOSO, ICIM, 309.
} 
expresión "cooperadores del orden episcopal" no puede entenderse como si la esencia del presbítero consistiera en ser meramente colaborador. Entonces, ¿cómo entender la expresión tan reiterada por el Vaticano II y por PDV?39

\subsection{Una fórmula con hondo arraigo eclesial}

Dos aspectos saltan a la vista inmediatamente: la reiteración de la idea en el magisterio de la Iglesia y la larga tradición teológica y eclesial de que viene precedida. "Cooperador, colaborador del obispo", ¿qué calificación teológica le corresponde? No se ha determinado si se trata de la definición dogmática de una verdad revelada o de un acto de economía eclesiástica; ha solucionado de facto, pero no de iure una controversia muy antigua que llega hasta el Vaticano $\mathrm{II}^{40}$, como reacción contra las tendencias presbiterales de Jerónimo, el Ambrosiaster y otros autores del siglo $\mathrm{V}^{41}$. Lo que queda claro es que hay que presentar teológicamente el presbiterado en referencia al episcopado; lo que habrá que precisar es la naturaleza de esa referencia-dependencia, de forma que quede a salvo la identidad presbiteral arraigada en el sacramento, su genuina raíz.

\subsection{Una tradición que agiganta la figura del obispo}

El obispo y la Trinidad. En una referencia analógica al misterio trinitario, al obispo se le asigna el lugar del Padre.

La tesis arranca teológicamente de Ignacio de Antioquía quien la sostiene con notable vigor. Lo que el Padre tiene de principio en la vida trinitaria, lo tiene el obispo al frente de la comunidad. Lo que el Padre es en el seno de la Trinidad, analógicamente lo es el obispo en la Iglesia. "El obispo ocupa el lugar de Dios" (Magn VI,1), es imagen del Padre (Cf. Trall III,1) pues éste es llamado por Ignacio "Obispo invisible" (Magn III,2) visibilizado para nosotros en el obispo. Ignacio recalca que el obispo es el

39 Encontramos esta expresión o similares no menos de 15 veces en los documentos del Vaticano II: LG 20c; 21a; 28b; CD 10a; 15a; 16c; 28a; 29a; 30a; 34a; PO 2b; 4a; 7a; 12a; OT 9a. Se hace amplio eco del concilio PDV: nn. 4.17.20.23...

40 Cf. F. FRANSEN, “Órdenes sagradas” en K.. RAHNER et alii (Dirs), Sacramentum mundi. Enciclopedia Teológica, V, Herder, Barcelona 1976, 33.

41 Cf. Ibid. 43. 
principio de la unidad eclesial por cuanto en la Iglesia representa al Padre, que es el principio dinámico de la unidad de Dios en el seno de la Trinidad.

Para Tertuliano, el obispo es el sacerdote por antonomasia; el término sacerdote se aplica al presbítero de manera derivada. Según este autor, el obispo, por ser el sumo sacerdote, rige toda doctrina y disciplina eclesiástica (Cf. De bapt. 17,1)

Cipriano concibe al obispo como el eje en torno al cual gira la Iglesia, y es el principio de unidad de la misma: "Si quis cum episcopo non est, in Ecclesia non esse" (Carta 66, VIII,3). Coincide con Tertuliano en considerar al obispo como el sacerdote por antonomasia y al presbítero por derivación (Cf. Carta 55,VIII; Carta 63, XIV,3).

El Pseudo-Dionisio va a jugar un papel decisivo. En su obra "De ecclesiastica hierarchia" expone la naturaleza del orden a partir del obispo, que abarca en sí las facultades de los presbíteros y de los ministros. Como, según su esquema teológico, la "ecclesiastica hierarchia" tiene que ser trasunto de la "divina hierarchia", el obispo funge lógicamente en la Iglesia el papel del Padre en el seno del misterio de Dios.

En conclusión. Según un estudio estadístico ${ }^{42}$, para Tertuliano, Cipriano y durante los siglos IV y V, el termino sacerdote se aplicaba casi exclusivamente al obispo.

\subsection{Cooperadores "en el ejercicio del ministerio"}

Vamos a avanzar en la precisión del tipo de relación del presbiterado respecto del episcopado. Estamos ante el punto central que hay que dilucidar. El dato firme que actúa cono sustrato es la raíz sacramental del planteamiento: hay "comunidad de altar" (LG 26a).

La peculiar vinculación del presbiterado al episcopado se despliega en tres direcciones principales: se debe al orden y ministerio compartido; además, se comparte el ejercicio del ministerio; en tercer lugar, nos movemos bajo el principio de la "comunión jerárquica"43. Las tres vertientes se detectan en el rito de ordenación del presbítero: el sacramento crea una

\footnotetext{
42 Cf. P.-P. GY, "Remarques sur le vocabulaire antique du sacerdoce chretien" en AA. VV., Études sur le sacrament de l'ordre, Paris 1957, 138.

43 Cf. R. SÁNCHEZ CHAMOSO, 258-263.
} 
red de comunión y armonía episcopado-presbiterado, y esto es capital porque aquí está en juego la dimensión apostólica del presbiterado

\subsubsection{Desde la "comunión” y la "eclesiología de comunión"}

Si nos preguntamos por la base, ésta no es otra que la Iglesia-comunión. En efecto, "la eclesiología de comunión" resulta decisiva para descubrir la identidad del presbítero, su misión en el pueblo de Dios y en el mundo" (PDV n.12). El presbítero es descrito como "hombre de comunión" (PDV nn.18b.43d). El ministerio del presbítero no es autónomo, sino que se inscribe en un marco comunional de ministerios eclesiales (Iglesia "toda ella ministerial"). El servicio que el presbítero presta a la comunión lo hace mancomunadamente con otros: "Es servidor de la Iglesia-comunión porque -unido al obispo y en estrecha relación con el presbiterio- constituye la unidad de la comunidad eclesial en la armonía de las diversas vocaciones, carismas y servicio" (PDV n. 16e).

\subsubsection{Referencias al obrar presbiteral}

Sigamos nuestra pesquisa teológica. “Cooperadores...”El termino tan reiterado en la tradición eclesial, ¿apunta a un contenido ontológico o más bien es una oportuna advertencia pastoral-disciplinar ante el peligro de concebir al presbítero distanciado del obispo, o autónomo?. Dicho en otros términos, ¿esa cooperación-dependencia respecto al episcopado se refiere al ser del presbítero o al actuar de su ministerio? Los que se inclinan por lo primero concluirán que la "cooperación” (subordinación y dependencia) es la expresión de la identidad presbiteral o de su más íntima naturaleza teológica. A mi modesto parecer, es la segunda propuesta la correcta. ¿Habrá que entender la "cooperación en clave de obediencia"?44 No compartimos esta interpretación, se aborda aquí un punto capital para el objetivo de nuestro trabajo.

44 Cf. LG 28a; 34a. Habrá que tener en cuenta los interesantes matices de la obediencia presbiteral que señala PDV n.28. Ya el concilio apunta este significativo matiz: "La obediencia sacerdotal, penetrada de espíritu de cooperación, se funda en la participación misma del ministerio episcopal, que se confiere a los presbíteros por el sacramento del orden y la misión canónica" (PO 7b). Pero, en todo caso, siempre es, ante todo, obediencia al servicio de Dios y de los hermanos (Cf. PO 15b), a través de las disposiciones ("missio canonica") de los rectores visibles de la Iglesia, asegurando así la "necesaria unidad". 
Se hace necesario metodológicamente distinguir dos niveles:

a) Origen del ministerio presbiteral, de carácter cristológico-sacramental en orden a la misión apostólica. Es el tema de la ontología o ser ministerial propio del presbítero, se trata de lo constitutivo-ontológico y esto se debe indiscutiblemente al sacramento;

b) Ejercicio del ministerio para la edificación de la comunidad eclesial, que no puede realizarse sin la comunión-cooperación con los sucesores de los apóstoles; es el actuar ministerial del presbítero o la perspectiva funcional. Se trata ahora del ejercicio del ministerio o su dimensión operativa, y esto se debe hacer indiscutiblemente en dependencia del obispo ${ }^{45}$.

\subsubsection{Testimonio de la Iglesia antigua}

Una mirada a los primeros tiempos de la Iglesia nos puede poner en la pista de la solución correcta; el presbítero depende del obispo en el ejercicio del ministerio, y así es su cooperador.

Ignacio de Antioquia, en la "Carta a los Esmirniotas", afirma tajantemente la necesidad de actuar ministerialmente en comunión-dependencia del obispo, o sea, sitúa su reflexión en el plano operativo. La simple lectura de los textos habla por si sola ${ }^{46}$. Ignacio no se refiere a la identidad sacramental del presbítero (o del diácono), sino al ejercicio de su ministerio, a su actividad ministerial, pero la ontología de esos ministerios, lo constitutivo del nuevo ser ministerial, la constitución en el ministerio es obra del Espíritu Santo, que es quien consagra; el obispo actúa como "ministro instituyente" o instrumento del que se vale el Espíritu Santo, al que invoca ("epíclesis") para que sea él quien realice la obra.

La comunión entre presbítero y obispo en el obrar ministerial queda además de manifiesto en la concepción ignaciana del "presbiterio", concebido como un todo del que forman parte el obispo y los presbíteros.

\footnotetext{
45 Ahora nos ocuparnos del segundo nivel. El primero se abordará en otro momento al tratar de la raíz o fuente de la identidad presbiteral.

46 "Que nadie, sin contar con el obispo, haga nada en cuanto atañe a la Iglesia. Sólo aquella eucaristía ha de tenerse por válida que se celebre por el obispo o por quien de él tenga autorización" (Ib. VIII, 1). "Sin contar con el obispo, no es lícito bautizar ni celebrar la eucaristía, sino, más bien, aquello que él apruebe, eso es también lo agradable a Dios, a fin de que cuanto hiziereis sea seguro y válido" (Ibid., VIII, 2) "El que a ocultas del obispo hace algo, rinde culto al diablo" (Ibid. IX, 1) (Subrayamos los términos que resaltan el carácter operativo de los textos).
} 
Otro testimonio que avala y refuerza lo anterior nos lo ofrece el "Ritual de la ordenación". En el interrogatorio a que son sometidos los ordenandos, se les pregunta: “¿Estáis dispuestos a desempeñar siempre el ministerio sacerdotal con el grado de presbíteros, como buenos colaboradores del orden episcopal?". Aparece también claro que se trata del ejercicio del ministerio, no de lo ontológico o constitutivo, de la identidad del presbítero.

\subsubsection{A la escucha del Vaticano II}

Llegamos al concilio Vaticano II, que debemos analizar en detalle para comprender cómo entiende al presbítero bajo la faceta de "cooperador del orden episcopal".

A modo de trasfondo, en una lectura en paralelo o por analogía, volvemos a referirnos al tipo de relación (cooperación, dependencia) entre primado y episcopado: el obispo ejerce el ministerio propio en el marco de la comunión-sumisión al Papa, pero el concilio ha dejado a salvo que el origen y la identidad (lo ontológico) del episcopado no deriva del Papa, sino del sacramento. La "comunión jerárquica" proclamada por el concilio se refiere directamente a la praxis ministerial, que el obispo no puede ejercer de forma autónoma.

De la relación Papa-obispos en el plano operativo pasemos ahora analógicamente a la relación obispo-presbíteros en el mismo plano. La Iglesia ha practicado y sigue practicando, a partir de un único sacramento del orden, una doble manera de conferir el sacerdocio ministerial: a los obispos se les confiere la plenitud del sacramento del orden"47, a los presbiteros se les confiere como "necesarios cooperadores de los obispos" (PO 7a). La cuestión, pues, se centra en el modo de ejercer el sacerdocio ministerial cada uno de ellos, no en el origen del poder sacerdotal. El Vaticano II se pronuncia con toda la claridad deseada sobre el modo de ejercer el ministerio presbiteral, siempre en dependencia del obispo: "De ellos dependen, en el ejercicio de su propia potestad, los presbíteros", "como próvidos cooperadores del orden episcopal" (LG 28a; CD 15a). Hay una íntima relación entre ser presbítero y ser cooperador del obispo, una y otra

\footnotetext{
${ }^{47}$ LG 21b. El obispo es llamado el "gran sacerdote de la grey" (SC 41a).
} 
cosa como efecto del sacramento del orden, pero son niveles distintos ${ }^{48}$. Quizá queda más clara aún la misma idea en este otro pasaje: "Han sido constituidos verdaderos sacerdotes del Nuevo Testamento para ser próvidos cooperadores del orden episcopal" (CD 15a). Se despeja así el peligro del presbítero autónomo en su praxis ministerial ${ }^{49}$ al resaltar la modalidad subordinada del ministerio presbiteral; no se puede entender un ministerio presbiteral que no sea cooperador del episcopado.

La modalidad subordinada del ministerio presbiteral en manera alguna resta importancia al sacerdocio presbiteral, que, en cuanto tal, no queda a merced de lo que el obispo pudiera determinar. El obispo tiene que respetar la necesidad e identidad propia del presbítero. El Vaticano II aporta también luz al respecto cuando califica a los presbíteros como "colaboradores y consejeros necesarios" del obispo (PO 7a); necesarios debido al sacramento que les otorga el ser ministerial, por lo que no dependen en su ser presbiteros de la discrecionalidad del obispo ${ }^{50}$. Relación sacramental, pues, entre episcopado y presbiterado, sin por ello cuestionar la raíz cristológico-sacramental (no episcopal) del ministerio presbiteral. Escuchemos de nuevo al concilio: "El ministerio de los presbíteros, por estar unido con el orden episcopal, participa de la autoridad con que Cristo mismo edifica, santifica y gobierna a su pueblo" (PO 2c), "ministerio que se confiere a los presbíteros por el sacramento del orden" (PO 7b), "consagrados de manera nueva a Dios por la recepción del orden, se convier-

48 LG 28a y P07a apuntan a estos niveles: orden y ministerio. "Todos los sacerdotes, tanto diocesanos como religiosos, están, pues, adscritos al cuerpo episcopal por razón del orden y del ministerio".

49 PO 7c rechaza esta eventual autonomía o insolidaridad del presbítero tanto respecto del episcopado como del presbiterio: "Ningún presbítero puede cumplir cabalmente su misión aislado o como por su cuenta, sino sólo uniendo sus fuerzas con otros presbíteros, bajo la dirección de los que están al frente de la Iglesia”. Quizá es más categórica PDV n.17, refiriéndose a todos los ministros ordenados: "El ministerio ordenado tiene una radical forma comunitaria y puede ser ejercido sólo como una tarea colectiva" (Los subrayados en el original).

50 “...participación misma del ministerio episcopal que se confiere a los presbíteros por el sacramento del orden'(PO 7b). Por su parte, PDV insiste: "Sin sacerdotes, la Iglesia no podría vivir aquella obediencia fundamental que se sitúa en el centro mismo de su existencia y de su misión en la historia" (n. 1). De ellos (sacerdotes) depende el futuro de la Iglesia, su desarrollo y su misión universal de salvación" (n.4). "El ministerio sacerdotal es insustituible para la vida de la Iglesia y del mundo" (n.10). La misma idea en el "mensaje de los Padres sinodales al Pueblo de Dios" citado en n.4. Presbíteros, "colaboradores necesarios" cf. R. SÁNCHEZ CHAMOSO, ICIM, 333-339. 
ten en instrumentos vivos de Cristo, sacerdote Eterno, para proseguir en el tiempo la obra admirable..." (PO 12a) ${ }^{51}$.

El sacramento asigna al presbítero una finalidad eclesial en comunión y dependencia del obispo ("grado subordinado"). El Vaticano II ha logrado unir en un magnífico texto la dimensión cristológico sacramental (configuración con Cristo Sacerdote, Cabeza y Pastor) la dimensión eclesiológica (para la edificación del Cuerpo de Cristo) y la dimensión operativa (cooperación con el obispo): "Por el sacramento del orden, se configuran los presbíteros con Cristo Sacerdote, como ministros de la Cabeza...para el ministerio...para construir y edificar todo su cuerpo, que es la Iglesia, como cooperadores del orden episcopal" (PO 12a).

\subsection{Naturaleza y tipo de "cooperación"}

Todavía nos tenemos que preguntar qué clase de "cooperación” se pide al presbítero y, para ello, hemos de remitirnos al fundamento teológico de la misma.

\subsection{1. "Cooperación" basada en el sacramento y como efecto del mismo}

El Vaticano II dice en un pasaje extremadamente cauto y perfilado que el "ministerio eclesiástico es de institución divina" (LG 28a)52 pero ni el Vaticano II ni antes Trento afirman directamente que sean de institución divina cada uno de los ministerios generados por el sacramento del orden 53 . El Vaticano II lo afirma del "ministerio eclesiástico" (en bloque),

51 El sacramento hace a los presbíteros "ministros de la Cabeza" al configurarlos con Cristo Cabeza". Por tanto, cooperadores, sí, del orden episcopal, pero antes y sobre todo "instrumentos vivos de Cristo" en cuyo nombre y por cuya causa actúan (PO 12a).

52 Cf. Nota 35. El Vaticano II va más allá de Trento y avala la tesis de la minoría que no prosperó en Trento.

53 Hay que advertir que, refiriéndose a los obispos, LG 20c enseña: "Los obispos han sucedido, por institución divina (divina institutione), a los apóstoles”. Quizá se apoye en este pasaje una interpretación sostenida por algún teólogo: "Cristo instituyó directamente el sacerdocio episcopal...El mismo directamente instituyó el episcopado". (J. ESPEJA, "Sacramentalidad del episcopado" en Teología Espiritual 19-20 (1963)107) A lo que anota otro teólogo actual: "Una afirmación más que arriesgada, si se tiene en cuenta la doctrina de Trento sobre el número septenario de los sacramentos, a no ser que se niegue la sacramentalidad del presbiterado" (R. ARNAU-GARCIA, Orden y ministerios, BAC, Madrid 2001, 190 nota 11). Hay también autores que deducen de LG 18 b que el colegio episcopal es de iure divino. 
añadiendo que en la historia "es ejercido en diversos órdenes por aquellos que desde antiguo vienen llamándose obispos, presbíteros y diáconos" (LG 28a) ${ }^{54}$. Adviértase que se resalta la unidad del ministerio ordenado, unidad que se sitúa a distinto nivel de la diversidad de ministerios que ejercen el "ministerio eclesiástico". Repitamos de nuevo que hay un único sacramento del orden y un único ministerio apostólico y eclesiástico del cual participan, cada uno a su modo, el episcopado, el presbiterado y el diaconado.

Estando así las cosas, el .modo de ejercer el ministerio se constituye en una de las claves diferenciadoras del ministerio ordenado ${ }^{55}$. La peculiaridad del ejercicio del ministerio del presbítero reside en hacerlo como cooperador del obispo, "en grado subordinado" 56 . No olvidemos que estamos moviéndonos en el plano del actuar o ejercicio del ministerio presbiteral.

Por su parte, el "Ritual de ordenación presbiteral" es bien expresivo. El obispo ordenante invoca al Espíritu en petición de colaboradores para guiar al pueblo. El Vaticano II se hace eco de este episodio (Cf. PO 7a) y cita a Núm 11,16-25, donde Moisés asocia a otros a su tarea, y "se propagó el espíritu de Moisés en las altas de aquellos setenta varones prudentes"; ése es el tenor de la cita bíblica (Núm 11,17). Pero el Espíritu invocado en la ordenación sacramental no es una partición del espíritu del ministro ordenante, como en el caso de Moisés, sino que es el Espíritu Santo. Nos hallamos en un nivel completamente distinto; ahora es el mismo sacramento, por la acción del Espíritu, el que hace a los presbíteros "cooperadores".

El gesto de la imposición de las manos y la invocación del Espíritu tiene matices distintos y produce efectos diversos: supremacía eclesial en el caso del obispo (recibe el "spiritus principalis") y cooperación en el caso del presbítero (recibe el "spiritus consilii" para ayudar al obispo a gobernar al pueblo). Pero el Espíritu invocado sobre el candidato al pres-

\footnotetext{
54 Cf. además LG .18. 19.2Oc.28a; PO 2.14.

55 "El obispo posee y ejerce el sacerdocio instituido por Cristo en plenitud eclesial a partir de su capitalidad al frente de una Iglesia particular mientras el presbítero lo ejerce como colaborador del obispo (R. ARNAU-GARCÍA, o..c., 184: subrayados nuestros).

56 En un próximo trabajo nos ocuparemos de esta temática: "plenitud" en el caso del obispo y "grado subordinado" en el presbítero. Con todo, téngase en cuenta que cada grado del ministerio ordenado tiene la plenitud propia del ministerio respectivo, no es una participación incompleta que necesite ser colmada por arriba.
} 
biterado es el que le constituye sacerdote para la edificación de la Iglesia en comunión de ministerio con el obispo.

Por consiguiente, el tipo de "cooperación" del presbítero tiene fundamento sacramental y se debe a la acción del Espíritu Santo, es efecto del sacramento y no de la promesa de obediencia hecha al obispo ordenante (signo que expresa visiblemente lo que ha efectuado el sacramento, signo, por otra parte, que realiza quien ya ha sido constituido sacerdote).

La "unidad de consagración y misión requiere su comunión jerárquica con el orden de los obispos" (PO 7a; cf. LG 28) Esto nos ayuda a comprende el tipo de "cooperación. Los presbíteros reciben de Cristo, vía sacramental, la misión apostólica, pero la ejercen en cuanto cooperadores del orden episcopal para cumplir la misión apostólica confiada por Cristo" (PO 2b). Pero siempre se trata de "colaboradores necesarios" 57 , por voluntad divina y debido al sacramento del orden.

Parece crear dificultad a nuestra exposición cuando afirma la liturgia y la teología que el presbítero recibe el sacerdocio "en grado subordinado", o que el suyo es un sacerdocio "de segundo grado". Habrá que entender estas expresiones, no exentas de dificultad como muestra la historia, a la luz del Vaticano II: ejercicio del ministerio presbiteral en comunión (subordinado) al obispo, presbítero y obispo mancomunados para la misma misión apostólica, pero respetando el modo peculiar asignado a cada uno. El "principio-comunión" no anula la diversidad de roles ni la peculiaridad específica de los ministerios ordenados, sino que los integra armónicamente en el servicio que cada uno presta a la misión apostólica. Hay complementariedad de ministerios ${ }^{58}$.

Nos estamos moviendo en el plano operativo del ministerio presbiteral, debiendo diferenciarlo del nivel ontológico, pero referidos ambos niveles al sacramento. Este integra los grados episcopal y presbiteral y enrola a ambos en la sucesión de los apóstoles, porque fueron instituidos en la

57 Cf. Nota 50.

58 Cf. Nota 44 donde presentamos la obediencia entendida en clave de solidaridad con la misión apostólica. PDV la califica de "apostólica y solidaria" con "especial carácter de pastoralidad" (n.28), exigida por el trabajo pastoral común: "La caridad pastoral apremia a los presbíteros a que, obrando en esta comunión, consagren por la obediencia su propia voluntad al servicio de Dios y de sus hermanos, aceptando y ejecutando con espíritu de fe lo que se manda o se recomienda por parte del Sumo Pontífice y del propio obispo, lo mismo que por otros superiores" (PC 15b). 
misión de los Doce. Y, como consecuencia de participar sacramentalmente de la misión conferida por Cristo a los apóstoles, obispo y presbítero han sido consagrados a Dios para actuar en la historia el plan de salvación. El sacramento del orden confiere a ambos el rol peculiar que los diferencia. Sentado esto como efecto del sacramento, hay que añadir que, así como el Papa determina el lugar y modo concreto de ejercer el rol del obispo por la "missio canonica", el obispo lo determina en el caso del presbítero mediante el correspondiente nombramiento para un cargo determinado.

\subsubsection{Glosa y despliegue de PDV}

La Exhortación postsinodal "Pastores dabo vobis" glosa y despliega al Vaticano II también en lo referente a la "cooperación" del presbítero con el obispo cuando escribe: "El ministerio ordenado, por su propia naturaleza, puede ser desempeñado solo en la medida en que el presbítero esté unido a Cristo con el orden presbiteral, y, por tanto, en la medida en que esté en comunión jerárquica con el propio obispo" (nn.17a; 20a). Varios motivos, entre los que se cuenta la "caridad pastoral" (cf. n.23d; PO 14) hacen que "el ministerio de los presbíteros sea, ante todo, comunión y colaboración responsable y necesaria con el obispo en su solicitud por la Iglesia" (n.117b). Pero son las razones teológicas de la "cooperación" las que hay que resaltar, porque no se trata primariamente de una simple cuestión de estrategia o de organización pastoral debidas a una planificación humana, sino que hay una raíz sacramental: "El presbítero está inserto sacramentalmente en la comunión con el obispo y con los otros presbíteros para servir al pueblo de Dios, que es la Iglesia" (n.12; cita PO 7-8) y prosigue enraizando la "cooperación" en el mismo sacramento: "Este origen sacramental se refleja y se prolonga en el ejercicio del ministerio presbiteral: del mysterium al ministerium. La unidad de los presbíteros con el obispo y entre sí no es algo añadido desde fuera a la naturaleza propia de su servicio, sino que expresa su esencia como solicitud de Cristo Sacerdote por su pueblo congregado por la unidad de la Santísima Trinidad" (n.74f).

A esta razón teológico-sacramental se debe añadir la que se deriva de la misma naturaleza del presbiterio (Cf. nn.28d; 31b; 74e.g; cita LG 28 y PO 7-8). La naturaleza colegial del presbiterio, fruto también del sacramento del orden, exige que los miembros que lo forman actúen en "cooperación" con el obispo en cuanto que es la cabeza del presbiterio, de 
modo análogo a como los obispos, miembros del colegio episcopal, deben "cooperar" con el Papa, cabeza de dicho colegio.

La teología postconciliar avala el planteamiento que hacemos sobre el ejercicio del ministerio presbiteral como lo específico de la relación con el obispo, dejando a salvo la fuente sacramental del ministerio ${ }^{59}$.

\subsection{El ministerio presbiteral visto desde sus destinatarios}

El Vaticano II y PDV han insistido en la intencionalidad última del ministerio ordenado, que no es otra que el servicio al pueblo de Dios. Hay que tener esto en cuenta al tratar del presbítero como "colaborador del orden episcopal".

Puede servirnos de marco referencial la opción capital del Vaticano II al anteponer en "Lumen gentium" el capítulo del pueblo de Dios al de la jerarquía, pues ésta existe y encuentra su razón de ser en servir al pueblo como muestra sin interrupción la historia bíblica de la vocación de personas singulares, los "ungidos" de Yahvé para servir al pueblo de Dios. La rica teología ministerial del Vaticano II abunda en la misma idea. El pueblo de Dios es el que justifica los múltiples ministerios eclesiales, lo que ha contribuido a calificar al Vaticano II como un concilio eminentemente pastoral.

Pero ha sido PDV, tras las huellas del concilio, el documento postconciliar que más claramente lo ha puesto de manifiesto. Llama la atención la insistencia y el énfasis en esta idea, expuesta con nítida claridad y en diversos registros. Por lo que toca al presbítero, repite que es "deudor para con el pueblo de Dios" (nn.26.70), que es "medio" de cara a un "fin", y éste es el sacerdocio común, la ontología cristiana, el pueblo de Dios ${ }^{60}$. Esta es la "dimensión eclesial” de la vocación presbiteral (Cf. n.37).

59 Aducimos dos testimonios muy recientes: "Ejercen un ministerio que es del mismo orden que el de los obispos y tienen las tres mismas tareas sacerdotales del anuncio de la palabra, de la santificación, en particular por la eucaristía, y del ejercicio de la autoridad de Cristo Pastor, pero lo hacen dentro de la sumisión y de la comunión con el obispo" (H. BOURGEOIS, a.c., 198 (Subrayado nuestro). "La consecuencia a sacar de aquí es doble: en primer lugar, hay que afirmar del presbítero su sacramental unión con Cristo Cabeza que le otorga la capitalidad para poder actuar en la Iglesia; en segundo lugar, se ha de comprender que se trata de capitalidad eclesiológicamente vicaria, ya que el presbítero la tiene recibida como cooperador del obispo" (R. ARNAU-GARCÍA, O.c., 165 (El subrayado es nuestro).

${ }^{60}$ La insistencia de PDV es llamativa: cf. nn.14.16.17.35. Es éste uno de los puntos de la doctrina conciliar que más desarrolla PDV. 
Cuando PDV aborda el tema de la "caridad pastoral"61, nos lo presenta cono el motor y la rampa que lanza al presbítero a la tarea de servir al pueblo de Dios, a fuer de ser representación-personificación de Cristo Pastor, Cabeza y Esposo de la Iglesia. Cuando PDV trata de la obediencia del presbítero, le asigna un "especial carácter de pastoralidad" (subrayado en el original), es decir, "se vive en un clima de constante disponibilidad a dejarse absorber, y casi devorar, por las necesidades y exigencias de la grey" (n.28f).

En conclusión: el presbítero es "cooperador del orden episcopal" pero esto regido por el principio superior de que obispo y presbítero están al servicio del pueblo de Dios, más aún, que ambos comparten, cada uno desde su rol eclesial, la responsabilidad de servir al pueblo de Dios. El presbítero lo hará en comunión y bajo la dirección del obispo, cono "cooperador" con él en la tarea común asignada sacramental y corporativamente al ministerio ordenado.

\subsection{Otros tipos de relación obispo-presbítero}

Podemos decir en líneas generales que los presbíteros representan al obispo en cuanto que actúan "bajo la autoridad del obispo" (LG 28b.e). Es una de sus funciones. El Vaticano II dice del párroco que "hace las veces del obispo" (SC 42a). Desde Ignacio de Antioquía, al presbítero se le encomienda una comunidad a modo de prolongación del obispo, que es la cabeza de la Iglesia particular. Esta representación se da de modo particular en la liturgia, como consecuencia de la doctrina sobre un altar, una eucaristía, un sacerdocio, un presbiterio, pero puede darse también bajo otros registros (Cf. PO 21a; SC 127a; PDV 60d; 66b).

Especial mención merece la relación con el obispo cuando el presbítero está al frente de una comunidad local, pues "reúne la familia de Dios en nombre del obispo" (LG 28b.e; PO 80). "En la administración de todos los sacramentos... los presbíteros se unen jerárquicamente de diversos modos con el obispo, y así lo hacen en cierto modo presente en cada una

61 Se ha señalado que la "caridad pastoral" es quizá el concepto-estrella de PDV, logrando un notable desarrollo de la doctrina conciliar. 
de las asambleas de los fieles" (PO $\left.5^{\mathrm{a}}\right)^{62}$. En el responsable pastoral de cada comunidad, se ve la presencia del obispo "principio de unidad de la Iglesia particular, sucesor de los apóstoles.

El presbítero al frente de una comunidad es el punto de enlace tanto con la Iglesia particular como con la universal; el obispo encarna la capitalidad eclesial que garantiza a cada comunidad la fidelidad a los orígenes apostólicos.

Otra peculiaridad de la relación presbíteros-obispo se deriva de la realidad sacramental-teológico-pastoral del presbiterio63. Este "cuerpo" colegial está presidido por el obispo como cabeza e incluye como miembros a todos los presbíteros. La peculiar relación-comunión se debe a que tanto la cabeza como los miembros son absolutamente necesarios para la existencia del presbiterio y, en último término, porque el sacramento del orden ha creado entre todos los que lo componen una comunión en el mismo sacerdocio y ministerio (PO 7a).

Por último, hay otra relación con el obispo considerado ahora como ministro ordenante del presbítero. A través del ejercicio del ministro ordenante, el presbítero es incorporado a la estructura apostólica de la Iglesia: "mediante el sacerdocio del obispo, el sacerdocio de segundo orden se incorpora a la estructura apostólica de la Iglesia. Así el presbítero, como los apóstoles, hace de embajador de Cristo. En esto se funda el carácter misionero de todo sacerdote" (PDV n.16b).

\subsection{Estilo peculiar de la relación entre obispo y presbíteros}

Se deduce de cuanto hemos expuesto un estilo peculiar en la relación obispo-presbíteros, caracterizado por un profundo sentido de familiaridad, una exigencia que implica por igual a ambos. El Vaticano II y PDV no han

\footnotetext{
62 cf, sobre todo, n.23; además, nn.21.24.27.29.30.31.33. 40.70.71.72.74. "Los presbíteros hacen presente al obispo, de alguna manera, en las reuniones locales concretas de los fieles, toma parcialmente sus oficios y solicitud, y los ejecutan con cuidado cotidiano" (SÍNODO DE LOS OBISPOS DE 1985, Relación final, II,C.6).

63 El presbiterio es la expresión a escala diocesana de la colegialidad de la Iglesia: cf. nota 27, sobre la base teológica y operativa sentada por Ignacio de Antioquía. La necesidad de una Teología del presbiterio se hace cada vez más necesaria para una genuina Teología del presbiterado. Cf. algunas ideas en R. SÁNCHEZ CHAMOSO, MNA, 386-389 y ICIM, 243-287.
} 
pasado por alto este punto, que debe mostrar visiblemente los lazos que se han creado a partir de la teología del ministerio ordenado. "Por razón de esta comunión en el mismo sacerdocio y ministerio, tengan los obispos a los presbíteros como hermanos y amigos suyos" (PO 7a; PDV 65d), como "hijos y amigos" (CD lbc ; LG 26b). Por su parte, los presbíteros consideren al obispo como "padre" (CD 28a; LG 28b), como "padre y amigo" (PDV 41c) o como "padre y pastor" (CD la; PDV b5d).

Este tipo peculiar de relación es de género distinto, se asienta en otras bases y, por tanto, rebasa el tipo de relación que existe en la sociedad entre sus miembros. Por otra parte, rebasa también las normas de cortesía, educación y pacífica convivencia para pasar a ser efecto del sacramento y ministerio compartidos con su importante incidencia pastoral ${ }^{64}$.

\subsection{Sugerencias para una terminología más apropiada}

Sabido es que la terminología (lenguaje) ha sido siempre un caballo de batalla para la teología y, por otra parte, que es uno de sus cometidos. Sabemos, historia teste, lo que ha costado con frecuencia encontrar los términos que expresen correctamente la fe que se profesa. También en nuestro tema nos encontramos con un problema de terminología ${ }^{65}$, a sabiendas que el lenguaje (los términos) no es inocente porque traduce un determinado pensamiento (conceptos) o modo de pensar y expresar la fe. En este orden de cosas y en esta tarea de búsqueda de una mejor terminología hacemos algunas sugerencias.

* ¿No sería más exacto y más fiel a la teología del Vaticano II en vez de "cooperan" decir que los presbíteros "comparten" el ministerio de Cristo y de la Iglesia con los obispos?. Hemos señalado antes que el Vaticano II habla de "comunión en el mismo sacerdocio y ministerio". Decir "cooperan, participan" del ministerio del obispo puede entenderse como "deriva de" el obispo, lo que no es correcto porque derivan del sacramento.

* ¿No sería mejor, en vez de decir “cooperador bajo la autoridad del obispo" en la acción ministerial, hablar de la consagración y misión compartidas cada ministro a su modo? Hay que mantener ciertamente la

64 Cf. R. SÁNCHEZ CHAMOSO, MNA, 530-533.

65 ¿Con qué nombre expresar adecuadamente qué es el presbítero? Por lo que se refiere al Vaticano II, cf. R. SÁNCHEZ CHAMOSO, MNA, 35-J; para un recorrido histórico, cf. Ibid, 412.419. 
"comunión jerárquica" (PO 7a), pero ¿hay que entenderla en clave de obediencia" en vez de hacerlo en clave de "corresponsabilidad"? La base de la relación obispo-presbíteros es primariamente teológica, no jurídica, moral o pastoral. Repetimos la base asentada por el Vaticano II: "Por razón de esta comunión en el mismo sacerdocio y ministerio. Por supuesto que la obediencia tiene sentido, pero la primera obediencia tanto para el obispo como para el presbítero se debe a la misión, en fidelidad insobornable al Evangelio".

* El término "cooperación", que inmediatamente evoca sumisión a alguien superior, puede ser sustituido sin perder lo que de válido encierra por los términos "solidaridad" y "corresponsabilidad" (Cf. PDV 17b; 41d), que expresan mejor la idea básica de comunión. Ciertamente se trata de "co-participación" con el obispo en la responsabilidad eclesial, y ahí se entronca precisamente el sentido teológico (no primariamente jurídico) de incardinación en una Iglesia particular (Cf. PD 31b).

* Al hablar del presbítero como "cooperador del orden episcopal" deberá sentarse claramente que la base teológica radica en la comunión de todos en el sacerdocio y en el ministerio De no hacerlo así, eludimos el ámbito teológico y nos recluimos en el plano jurídico. PDV acierta a conjugar ambos elementos: "El ministerio de los presbíteros es, ante todo, comunión y colaboración responsable y necesaria con el ministerio del obispo" (n.17b).

* El Vaticano II llana a los presbíteros "cooperadores del orden episcopal", no solo de un obispo particular. Por su parte, el "Ritual de la ordenación" habla de la obediencia del ordenado al obispo ordenante y a sus sucesores. Habría que resaltar más este punto. El sacramento no hace súbditos de una persona, sino colaboradores para una tarea. En realidad, los presbíteros con "cooperadores" juntamente con el obispo en la misión apostólica. A ésta se deben uno y otros.

* Es conveniente hacer una distinción para aclararnos. En perspectiva canónica, los presbíteros son colaboradores del Papa o de los Obispos, y el derecho expresa esto en términos de exención e incardinación. Pero en perspectiva teológica, los presbíteros son colaboradores del colegio episcopal en la misión apostólica y, por tanto, del Papa (aunque no sean exentos) y de todo el orden episcopal (aunque sean exentos). Exención e incardinación pertenecen al derecho eclesiástico y por ello pueden modificarse; lo que no puede alterarse es la perspectiva teológica. 
Con estas sugerencias sobre terminología hemos tratado de expresar más fielmente la fe sobre el ministerio presbiteral. No somos tan ingenuos que con ello se haya resuelto la honda problemática aquí planteada, pero quizá pueda ser una ayuda para aclarar mejor algunos puntos. No otro es el papel de la teología, siempre "en camino". 